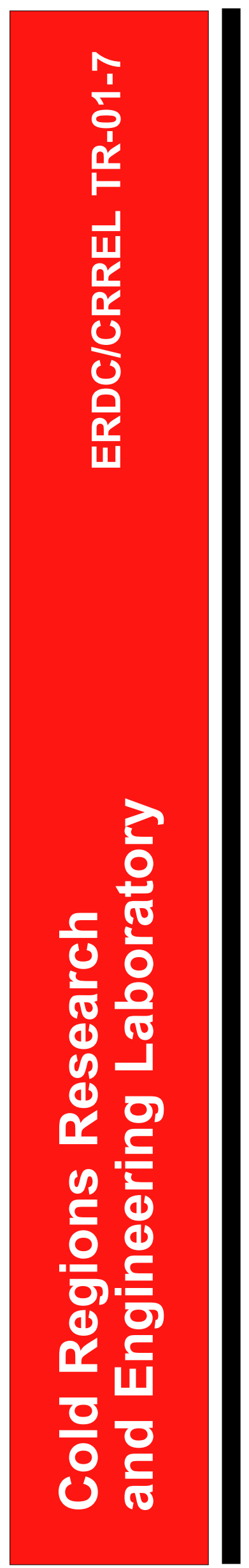

Characterizing Range Scrap and Developing Quality Assurance Coupons for Hot Gas Decontamination Trials

Alan D. Hewitt

March 2001 
Abstract: Characterization and decontamination of range scrap are relatively new compliance issues for military training and testing facilities. This report describes the development of an approach for characterizing energetic residues on range scrap and a method to assess the performance of a low-cost hot gas decontamination system. The procedure used to identify secondary explosives on range scrap involves a twotiered analytical process. Initially, simple wet chemical tests that can be interpreted visually were used on-site to screen readily accessible and partly enclosed surfaces, then samples were collected for analytespecific methods of analysis. Another objective of this study was to develop quality assurance samples that could be used to optimize the hot gas decontamination treatment system and, thereafter, to satisfy regulatory agency requirements for monitoring its performance.

How to get copies of ERDC technical publications:

Department of Defense personnel and contractors may order reports through the Defense Technical Information Center:

DTIC-BR SUITE 0944

8725 JOHN J KINGMAN RD

FT BELVOIR VA 22060-6218

Telephone (800) 225-3842

E-mail help@dtic.mil msorders@dtic.mil

WWW http://www.dtic.mil/

All others may order reports through the National Technical Information Service:

NTIS

5285 PORT ROYAL RD

SPRINGFIELD VA 22161

Telephone (703) 487-4650

(703) 487-4639 (TDD for the hearing-impaired)

E-mail_orders@ntis.fedworld.gov

WWW http://www.ntis.gov/index.html

For information on all aspects of the Engineer Research and Development Center, visit our World

Wide Web site:

http://www.erdc.usace.army.mil 
Technical Report

ERDC/CRREL TR-01-7

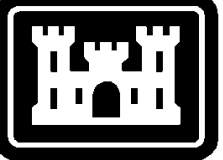

US Army Corps

of Engineers ${ }_{\circledast}$

Engineer Research and

Development Center

\section{Characterizing Range Scrap and Developing Quality Assurance Coupons for Hot Gas Decontamination Trials}

Alan D. Hewitt

March 2001 


\section{PREFACE}

This report was prepared by Alan D. Hewitt, Research Physical Scientist, Environmental Sciences Branch, U.S. Army Engineer Research and Development Center, Cold Regions Research and Engineering Laboratory.

Funding for this work was provided by the U.S. Army Environmental Center, Martin Stutz, Project Monitor. The author thanks Dr. Thomas Jenkins (CRREL) and Martin Stutz for providing technical reviews.

The contents of this report are not to be used for advertising or promotional purposes. Citation of brand names does not constitute an official endorsement or approval of the use of such commercial products. 


\title{
Characterizing Range Scrap and Developing Quality Assurance Coupons for Hot Gas Decontamination Trials
}

\author{
ALAN D. HEWITT
}

\section{INTRODUCTION}

The Army is currently evaluating hot gas treatment as an environmentally acceptable way to decontaminate the metallic debris that result from military training and testing. Residues of explosives degrade when they are exposed to moderate temperatures $\left(500-600^{\circ} \mathrm{F}\right.$, $\left.260-316^{\circ} \mathrm{C}\right)$; therefore, a low-cost hot gas decontamination (HGD) system has been proposed as an economical way to remediate the metallic debris to the $5 \times$ clean up standard (Parsons 1998). So that the off-gas stream from this treatment process does not need treatment itself, the range scrap should be mainly metallic debris; that is, it should be free of large pieces of plastic or rubber. To optimize and validate the effectiveness of the HGD technology, on-site analytical methods to characterize energetic residues on range scrap and protocols for quality assurance (QA) samples are needed.

The presence of energetic residues on range scrap has been reported by Jenkins et al. (1997). In their study, they immersed a 7-g piece of metallic debris from a LAW rocket in acetone to extract surface residues. This experiment established the presence of octahydro1,3,5,7-tetranitro-1,3,5,7-tetrazocine (HMX) and 2, 4, 6-trinitrotoluene (TNT) from the octol that was used as the main charge in the LAW rocket. Walsh et al. (1993) pointed to other explosives that are likely to be present at sites contaminated with army munitions. Their study, which compiled data from several sites where soil samples had been analyzed by Method 8330, established the following order from the most to least frequently detected explosives: TNT, 2,4-dinitrotoluene (2,4DNT), 1,3,5-trinitrobenzene (TNB), 1,3,5-hexahydro1,3,5-trinitrotriazine (RDX), 1,3-dinitrobenzene (DNB), 2-amino-4,6-dinitrotoluene (2AmDNT), HMX, methyl2,4,6-trintrophenylnitramine (Tetryl), 2,6-dintrotoluene (2,6-DNT), and 4-amino-2,6-dinitrotoluene
(4AmDNT). We can see that several explosives are likely to be associated with range scrap; however, several of these (2,4-DNT, 2,6-DNT, TNB, DNB, $2 \mathrm{AmDNT}$, and $4 \mathrm{AmDNT}$ ) are either impurities or break-down products of TNT, RDX, and HMX. We anticipate that these energetic residues will be extremely heterogeneous on range scrap. Therefore, a simple screening test would help to establish their presence and to control the number of samples that would have undetectable concentrations of explosives.

Currently, there are no standardized protocols for assessing energetic residues on the surfaces of range scrap. However, there are documented procedures for wiping relatively smooth surfaces to quantitatively assess lead in dust (ASTM 1999). Metallic range scrap is composed of a wide variety of objects of irregular shapes and sizes that often have rough (pitted), highly oxidized surfaces. In addition, there can be deep crevices, folded joints, and partly enclosed cavities. When the data quality objective is to identify the presence and type of explosive residues, sampling procedures similar to those developed for collecting lead in dust can be used, coupled with a single step or tiered analysis protocol.

Inexpensive on-site colorimetric and enzyme immunoassay detection methods exist for both TNT and RDX (Crockett et al. 1997). Colorimetric-based methods also exist for 2,4-DNT (Jenkins and Walsh 1992) and ammonium picrate (Thorne and Jenkins 1995), and the RDX colorimetric method can be used to estimate HMX concentrations, when this explosive is present at concentrations several orders of magnitude higher than RDX (Jenkins et al. 1998). The RDX colorimetric procedure will also detect nitrate esters (nitrocellulose $[\mathrm{NC}]$, nitroglycerin $[\mathrm{NG}]$, and pentaerythritol tetranitrate [PETN]) when they are present in high concentrations (Crockett et al. 1997). Because these colo- 
rimetric methods respond to whole groups of compounds, such as nitroaromatics or nitramines/nitrate esters, they are more suitable than immunoassay kits for screening for residues of explosives. In addition, these colorimeteric tests use a solvent extraction step. Therefore, one aliquot from a solvent extract, wipe, or rinse sample could be used to initially screen for the presence of the explosives (nitroaromatic, nitramine and nitrate esters, and ammonium picrate/picric acid), and a second aliquot could be analyzed with an analytespecific method of detection.

Detailed analysis of those samples positively responding to field screening tests is necessary to specify which explosives are present. In addition, an on-site analysis could help identify a suspect aggregate of materials as being an explosive. Unconsumed explosive materials are likely to associate with munitions that go low order (do not explode completely). Therefore, as a precaution, large pieces of debris that can be recognized as a munition should be treated with extreme care. Samples taken of unexploded residues are likely to have concentrations in the extract that require dilution prior to shipping and instrumental analysis.

Analyte-specific analysis could be done on-site with a field-portable gas chromatograph (GC) equipped with a thermionic detector (TID) that is selective for compounds containing nitro $\left(\mathrm{NO}_{2}\right)$ functional groups (Hewitt and Jenkins 1999, Hewitt et al. 2000). The SRI $8610 \mathrm{C} \mathrm{GC/TID} \mathrm{(Torrance,} \mathrm{California)} \mathrm{is} \mathrm{well} \mathrm{suited} \mathrm{for}$ this purpose because it operates with little auxiliary support. A TID is an electrically heated emission source composed of a ceramic bead impregnated with an alkali metal (Patterson 1986). When compounds containing nitro functional groups, e.g., nitroaromatic, nitramine, and nitrate esters, impinge on the surface of a TID, they are selectively ionized and measured with a collector electrode. This instrument is very transportable, robust, and economical (less than \$9000), and is capable of rapidly detecting all of previously mentioned explosives, with the exception of ammonium picrate and nitrocellulose (Hewitt et al. 2000). Off-site analysis could be done using either Method 8330 or 8095 (U.S. EPA 1995, 1999).

HGD has been successfully demonstrated at the Cornhusker Army Ammunition Plant, Nebraska; Hawthorne Army Depot, Nevada; and the Alabama Ammunition Plant, Alabama (Parson 1998). These trials used either existing buildings or metal bins to hold the metal scrap during thermal treatment and often included an off-gas treatment system. Since large piles of range scrap exist at Army, Navy, and Air Force installations, a HGD system that is portable and uses locally obtainable materials for the majority of its construction should be more cost effective, assuming it can produce the effectiveness of the previous designs. Currently, an HGD system, composed of a propane air heater and distribution assembly, a thermal blanket (i.e., insulation and chicken wire) cover, thermocouples, and data acquisition system, is being proposed for this task. This HGD system will be able to treat a scrap pile that may be as large as $2.4 \times 6.1 \times 9.1 \mathrm{~m}(\mathrm{~h}, \mathrm{w}, \mathrm{l})$. Because there are several design changes from previous tests, temperature-time (heat soak) criteria for the decontamination process will have to be established. Therefore, in addition to monitoring the temperature at several locations in the scrap pile and the treatment period, QA samples should be placed at strategic locations (near thermocouples) so that how completely the analyte decomposes can be assessed.

This report, therefore, addresses two separate topics: first, it investigates methods for detecting and characterizing residues of explosives on range scrap, and, second, it develops QA samples that can be used to verify the performance of the HGD system. The eventual product of this effort and others is to document protocols that can be used as guidance for characterizing range scrap and verifying HGD systems.

\section{MATERIALS}

\section{Design criteria for the QA samples}

The quality assurance (QA) samples must resemble the metallic materials to be treated and be spiked with approximately $1 \mathrm{mg}$ quantities of the explosives analytes found at a given facility. Henceforth, the metal materials (plates) that were spiked will be called coupons. In addition to these coupons, pieces of rangecontaminated scrap will also be used as part of the QA program. These pieces of scrap should have visible signs of residues of explosives on their surfaces and have given a positive response to a screening test. Both the coupons and representative range scrap should be housed in a chamber that can be easily recovered from the materials after HGD treatment. Lastly, this chamber and the coupons must maintain their physical integrity over a 6 -hour period while being heated to $1000^{\circ} \mathrm{F}\left(538^{\circ} \mathrm{C}\right)$.

\section{Coupons}

Metal coupons were made by cutting $1.5-\times 1.5-\mathrm{cm}$ squares from a $0.8-\mathrm{mm}$-thick sheet of aluminum and a 1.6-mm-thick sheet of steel. A dimple (slight depression) was made in the center of each coupon with a $4.8-\mathrm{mm}$ center punch to hold (concentrate) the liquid aliquots used to transfer the analytes. Next, all the surfaces of the steel coupons were rapidly oxidized using dilute solutions of hydrochloric and nitric acid and aque- 
ous solutions of saturated sodium chloride. Both types of metal coupons were then repeatedly heated to temperatures greater than $1100^{\circ} \mathrm{F}\left(593^{\circ} \mathrm{C}\right)$. This size coupon is large enough to hold a $5-\mu \mathrm{L}$ aliquot of acetonitrile or acetone on the surface during spiking, yet small enough to fit into, and lie flat on the bottom of, a standard 40- or 20-mL VOA vial for residue recovery. When in this position (lying flat on the bottom of the vial), the coupon is submersed in $1 \mathrm{~mL}$ of extraction solvent.

\section{Chambers}

Chambers for housing one or more coupons (e.g., an aluminum and steel coupon), a small piece of range scrap, and perhaps a thermocouple, were made from standard zinc-plated-steel electrical switch boxes (Fig. 1). These boxes had four 4.7-mm holes in the bottom, and had an additional $4.7-\mathrm{mm}$ hole drilled into each of the four side walls. Zinc-coated wire fencing $(6.4 \times 6.4$ $\mathrm{mm}$ ) was molded into platforms to hold coupons firmly near the center of the chamber, while leaving space for a small (less than $2.5 \times 5 \times 2.5 \mathrm{~cm}[\mathrm{~h}, \mathrm{l}, \mathrm{w}]$ ) piece of range scrap. If necessary, a thermocouple could also be located within the chamber by removing one of the knock-out tabs and using a standard metal wire lock to secure the wire lead. This chamber and wire mesh cage did not physically deform when exposed to $1100^{\circ} \mathrm{F}$ $\left(593^{\circ} \mathrm{C}\right)$ for 6 hours. However, this thermal treatment did turn the zinc plating to a white or yellowish color, and in some places (along edges) the plating became friable.

\section{Stock solutions of TNT, RDX, and HMX}

The solubility of TNT in acetone is about $109 \mathrm{~g}$ per $100 \mathrm{~g}$ at $20^{\circ} \mathrm{C}$, and the solubility is nearly as high in acetonitrile. A concentrated stock solution was prepared by dissolving $1 \mathrm{~g}$ of TNT into $5 \mathrm{~mL}$ of acetonitrile $(0.2$ g TNT/mL).

The solubility of RDX in acetonitrile is about $12 \mathrm{~g}$ per $100 \mathrm{~g}$ at $30^{\circ} \mathrm{C}$. To prepare a concentrated stock solution for RDX, $1 \mathrm{~g}$ was dissolved into $25 \mathrm{~mL}$ of acetonitrile $(0.04 \mathrm{~g} \mathrm{RDX} / \mathrm{mL})$.

The solubility of HMX in acetonitrile is about $2 \mathrm{~g}$ per $100 \mathrm{~mL}$. To prepare a concentrated stock solution, $0.1 \mathrm{~g}$ was dissolved in $5 \mathrm{~mL}$ of acetonitrile $(0.02 \mathrm{~g} \mathrm{HMX} /$ $\mathrm{mL})$. Several of the larger crystals $(0.25 \times 0.25 \mathrm{~mm})$ of HMX did not dissolve when this stock solution was prepared, so a concentration lower than $0.02 \mathrm{mg} / \mathrm{L}$ was anticipated.

All stock solutions were transferred to amber glass bottles with Teflon-lined septum screw caps that were stored at room temperature. Periodically, the threads of these bottles needed to be wiped with a solvent-moistened towel to remove a deposit of crystals. The formation of crystals and difficulties encountered in the preparation of these concentrated solutions were two unforeseen problems that should be addressed in the

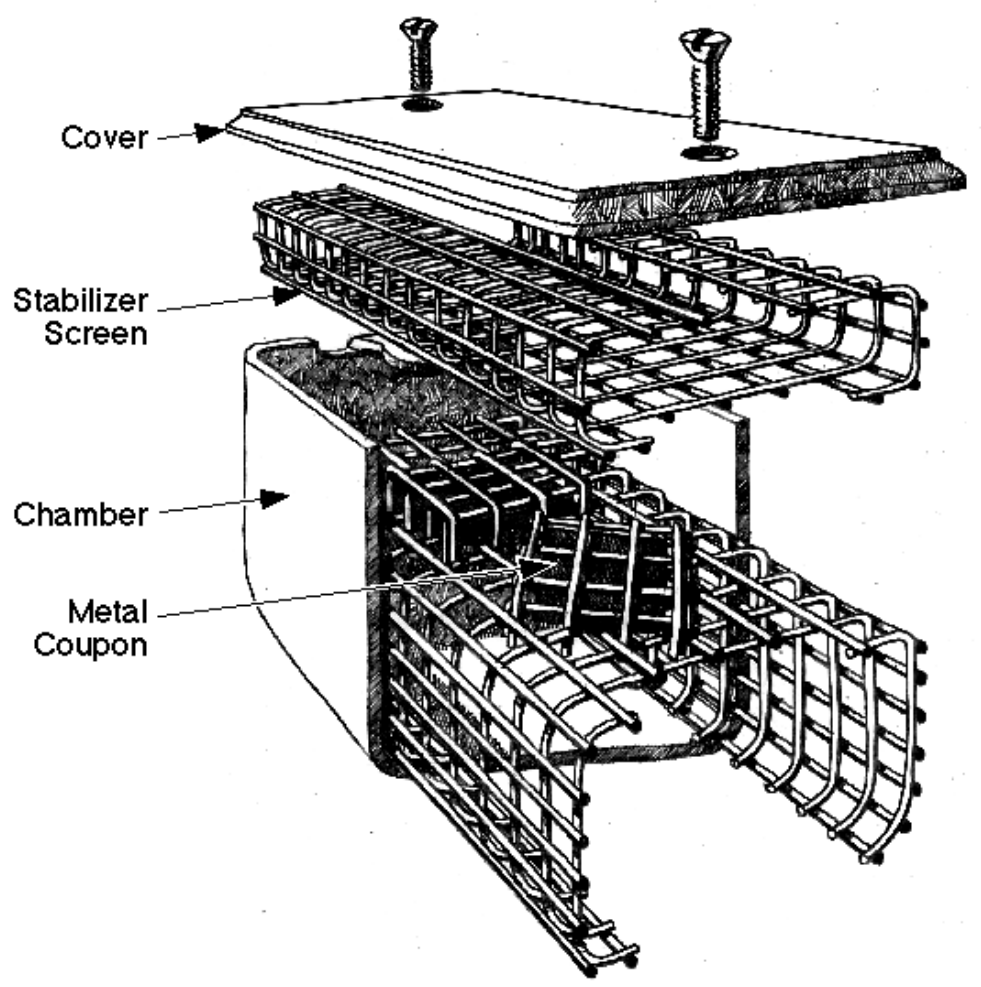

Figure 1. Chamber for housing one or more coupons. 
future, for both safety and accuracy concerns. These problems, most likely, can be avoided by purchasing commercial stock standards and storing them in a freezer. Concentrated standards of TNT $(50.0 \mathrm{mg} / \mathrm{mL}$ in acetone), RDX (20.0 $\mathrm{mg} / \mathrm{mL}$ in a mixture of MEK:methanol:acetone), and HMX $(20.0 \mathrm{mg} / \mathrm{mL}$ in methanol) are available from AccuStandard Inc. (New Haven, Connecticut).

\section{Instrumentation}

A field-transportable SRI Model 8610C gas chromatograph, equipped with a heated $\left(250^{\circ} \mathrm{C}\right)$ TID detector selective for nitro groups, a heated $\left(225^{\circ} \mathrm{C}\right)$ oncolumn injection port, and an internal air compressor, was used for this study. Separations were performed on a Crossbond $100 \%$ dimethyl polysiloxane column, $15 \mathrm{~m} \times 0.53 \mathrm{~mm}$ i.d., $1.5 \mu \mathrm{m}$ (DB-1), using the following temperature program: $145^{\circ} \mathrm{C}$ for 0.5 minutes, ramp to $150^{\circ} \mathrm{C}$ at $5^{\circ} \mathrm{C} / \mathrm{min}$, ramp from 150 to $250^{\circ} \mathrm{C}$ at $20^{\circ} \mathrm{C} / \mathrm{min}$, hold at $250^{\circ} \mathrm{C}$ for 0.5 minutes. The TID current was set at $-3.40 \mathrm{~V}$ and the carrier gas was supplied from an auxiliary nitrogen cylinder. The carrier gas was set at $15 \mathrm{psi}(103.4 \mathrm{kPa})$ for a column flow of 37.5 $\mathrm{mL} / \mathrm{min}$. The on-board air compressor was set at 5 psi $(34.5 \mathrm{kPa})$ to supply gas to the detector at $25 \mathrm{~mL} / \mathrm{min}$. Injections of $1 \mu \mathrm{L}$ were made manually with a $10-\mu \mathrm{L}$ glass syringe (SGE) equipped with a $7.0-\mathrm{cm}-$ long needle. Under these conditions, detection limits for TNT, RDX, and HMX are expected to be about 0.01 , 0.5 , and $5.0 \mu \mathrm{g} / \mathrm{mL}$, respectively.

\section{EXPERIMENTS}

\section{Site visit}

The Aberdeen Test Center (ATC) was visited on 1 and 2 May 2000 to establish which explosives compounds were most prevalent on range scrap there. In all, three different locations were visited. The first was a light armor test range. Here, range scrap had been collected and placed in a large metal bin, which contained pieces of an RDX material and some metal debris with surface smears of RDX. The second location, Dump 3, had wooden crates containing 155- and 175$\mathrm{mm}$ rounds that had been cut open. Most of these rounds had been buried in damp soil for about 20 years before they were collected and prepared for disposal, and were heavily corroded (oxidized). The third area consisted of two locations on the grounds of the Army Research Laboratory (ARL). At the first location there were large witness plates that had been cleared for scrap metal recycling inside a secured compound. The second location was a test pad with a wide variety of materials that had been partly segregated into metal bins and piles. At the test pad there were nitrocellulose propellant rods ( 2 in. $[5.1 \mathrm{~cm}]$ long $\times 0.75$ in. $[1.9 \mathrm{~cm}]$ diameter $)$ scattered over the general area.

A colorimetric screening test was used during this site visit to help determine which pieces of range scrap and other materials should be sampled for off-site laboratory analysis. Several positive colorimetric results were obtained at the first location, and a couple were obtained at the ARL test pad. All of the pieces of range scrap that responded positively to the colorimetric screening test were sampled for off-site analysis, along with pieces of material that were likely to retain (sorb) explosive signatures. In all 37 samples were taken for off-site analysis. The majority of these samples were wipes, which were obtained using a small-diameter (1.5 $\mathrm{cm})$ filter paper that had been soaked in methanol. These wipes were placed on the surfaces of the range scrap. After drying, they were folded and placed in a $2-\mathrm{mL}$ amber vial. Other types of samples taken during this initial visit were pieces of rubber/plastic gaskets, waxy substances, and soil (debris particles) collected from the bottom of the scrap bins. Appendix A gives a brief description of each of these samples.

The colorimetric tests used to screen for explosive residues on-site were done using the Expray kit (Mistral Security, Inc.; available from Plexus Scientific, Silver Spring, Maryland). These tests use reagents that identify explosives on the basis of Janowsky and Griess reactions. The Expray kit comes in a small, lightweight (less than $1.4 \mathrm{~kg}$ ) case that contains three aerosol cans for dispensing chemical reagents and some paper for wiping surfaces. To screen range scrap, the first step was to wipe (rub) exposed surfaces with a white sheet of paper (100 test sheets are supplied with the kit, or any white filter paper could be used). For sampling soils or other fine particles, a small quantity ( 0.5 to $1 \mathrm{~g}$ ) was placed in the middle of 47-mm pieces of glass fiber filter paper, then soaked with acetone (approximately twice the volume as weight). Then the filter paper was folded over and placed on a clean white surface. Next, the surface of the wipe or folded filter paper was sprayed, in accordance with the kit instructions. If a color appears after the first aerosol is applied, then polynitroaromatics (e.g., TNT, TNB, DNT, Picric acid, tetryl, etc.) are present. Some of the colors that may appear after this first aerosol is applied are blue, red, or orange. After the second aerosol is sprayed, the formation of a pink color indicates the presence of nitramines or nitrate esters (e.g., RDX, HMX, NG, PETN, NC, NQ, and tetryl, etc.). Next, the sample is sprayed with the third aerosol. If a pink color appears only after applying the third aerosol, then the presence of an inorganic nitrate (ammonium, potassium, sodium, barium, strontium nitrate, or black powder) is indicated. This 
screening method can easily show the presence of 0.5 $\mu \mathrm{g}$ of an explosive analyte when concentrated in a discrete location on a white surface (filter paper). For soil, a sample containing $4 \pm 1 \mathrm{mg}$ TNT/ $\mathrm{kg}$ was found to give a visible response using the above procedure.

All of the samples listed in Appendix A were returned to the Cold Regions Research and Engineering Laboratory (CRREL) for extraction and analysis. The samples were extracted with acetone by adding $1 \mathrm{~mL}$ to the auto sampler vials $(2 \mathrm{~mL})$ that contained the filter paper, soil, or small pieces of rubber/plastic gasket materials, while up to $10 \mathrm{~mL}$ was added to larger VOA vials $(20 \mathrm{~mL})$ that contained waxy substances. After initially analyzing all of the samples by GC/TID, several were reanalyzed by Method 8095 (U.S. EPA 1999) after they were appropriately diluted.

\section{Coupon performance}

Experiments assessed the QA coupons, their handling, and the efficiency of different methods of wiping their surface to quantitatively recover the residues of explosives. Many of these experiments used steel and aluminum coupons spiked with approximately 1 mg of TNT, RDX, and HMX. The coupons were spiked by sequentially adding $5-\mu \mathrm{L}$ aliquots of the stock solutions prepared in-house (mentioned previously) and allowing the solvent to evaporate. The aliquots were placed directly onto the surface of the coupon with a $10-\mu \mathrm{L}$ glass syringe (Hamilton); the solvent evaporated in less than 0.5 minutes. The spike aliquot appeared to remain in the dimple on the aluminum coupons, while often the entire top surface of the rusted steel coupons became visibly wetted. Coupons were spiked in batches, so that each one in the batch was treated with a single aliquot prior to the start of the next treatment round. The coupons were spiked with the HMX solution first, followed by RDX, then TNT. To achieve concentrations close to the target level of $1 \mathrm{mg}$ for each explosive, ten, five, and one 5- $\mu \mathrm{L}$ aliquots of the HMX, RDX, and TNT stock solutions, respectively, were placed on each coupon. For a batch of 12 coupons, this spiking process took approximately 20 minutes to complete. In addition to the experiments that involved wiping the surface of a QA coupon, one experiment was performed using range scrap.

\section{Coupon preparation, thermal treatment, and storage experiments}

The initial experiments assessed the following:

- The reproducibility of the QA coupons.

- The effect of thermal treatment on the QA coupons.

- The stability of the explosives on the coupons under two storage conditions.
Coupons of both types of metal, from three different preparation batches, were each placed in a $20-\mathrm{mL}$ VOA vial and extracted with $1 \mathrm{~mL}$ of acetone. Analyses of these extracts were used to assess the precision of the spiking procedure. Triplicate coupons of both types of metal were heated for 1 hour at $500 \pm 20^{\circ} \mathrm{F}$ $\left(260 \pm 6.6^{\circ} \mathrm{C}\right)$ in a muffle furnace. Following this thermal treatment, each type of metal coupon was combined into a single 20 -mL VOA vial (composited) and extracted with $3 \mathrm{~mL}$ of acetone. This experiment assessed the efficiency of thermal decomposition under this condition.

Two further experiments assessed the concentration stability of TNT, RDX, and HMX on the coupons during storage. In one experiment, triplicate QA coupons of both metals were stored in a plastic dish that was held at room temperature $\left(21 \pm 2^{\circ} \mathrm{C}\right)$ for 7 days. In the other, one of each type of metal coupon was placed in three separate chambers (electrical boxes), then each chamber was wrapped with aluminum foil and placed in a freezer $\left(-12 \pm 3^{\circ} \mathrm{C}\right)$ for 14 days. After these storage periods were over, individual coupons were placed into a VOA vial and extracted with $1 \mathrm{~mL}$ of acetone.

\section{Wiping and sample preparation experiments}

Several experiments assessed different techniques of wiping the coupon surface to recover the explosive residues. In addition, a couple of different sample preparation procedures were evaluated. For assessing wiping techniques, triplicate QA coupons of both types of metals were used.

For the first technique, a 1.5 -cm-diameter filter paper (Whatman, type 1), soaked in methanol, was pressed onto the coupons (approximately $80 \%$ coverage) with the aid of clean stainless steel tweezers. Once each filter paper had dried, it was folded (using the tweezers) and placed into a separate $2-\mathrm{mL}$ amber glass vial and extracted with $1.0 \mathrm{~mL}$ of acetone.

For the second technique, the entire spiked surface of the coupon was wiped several times with a $1.5-\mathrm{cm}$ diameter filter that had been soaked in acetone. As before, the filter paper was allowed to dry, then folded and placed in a 2-mL amber glass vial for extraction.

For the third technique, a Q-tip (paper post with a cotton swab on each end) that had one end soaked in acetone was first pressed against the wall of the vessel to removed excess solvent. Then, the entire top surface of the coupon was rubbed at least twice while it was held on the table surface with clean metal tweezers. The wetted end of the Q-tip was then inserted into the mouth of a 2-mL amber vial, the tip was cut off with scissors, and it was allowed to air dry. Then it was extracted with $1.0 \mathrm{~mL}$ of acetone.

Cotton balls were used for the fourth test. Before a 
coupon was wiped, each cotton ball (held with clean tweezers) was soaked in acetone (they hold approximately $4 \mathrm{~mL}$ of acetone). Then, the excess solvent was removed by pressing the ball against the side of a glass bottle and patting it on a small paper towel (Kim wipe). The top surface of a coupon was wiped several times, while the coupon was held above a clean surface with tweezers. Holding the coupon in the air limited, but did not prevent, excess solvent from running onto other surfaces. After wiping, the cotton ball was transferred to a $20-\mathrm{mL}$ VOA vial. These vials were left uncapped and placed on the front edge of an exhaust hood to allow the cotton balls to air dry before being extracted with $10 \mathrm{~mL}$ of acetone.

Lastly, a cotton ball moistened with only $1.0 \mathrm{~mL}$ of acetone was used to wipe the coupons. For this experiment, each cotton ball was moistened inside a $20-\mathrm{mL}$ VOA vial by adding $1.0 \mathrm{~mL}$ of acetone. After wiping, the swab was returned to the VOA vial, allowed to air dry, then extracted with $7 \mathrm{~mL}$ of acetone. This change in procedure prevented the loss of solvent during the wiping process.

\section{Range scrap wiping experiment}

Three pieces of a hand grenade that had been a low order detonation were used for an initial range scrap wiping experiment. Before this hand grenade was tested, several tests had shown that there were residues of explosives present on its interior surface. The residuecovered surfaces of these three hand grenade pieces (3.0 to $4.1 \mathrm{~cm}^{2}$ ) were each wiped with a cotton ball moistened with $1.0 \mathrm{~mL}$ of acetone. After wiping, each fragment was placed in small glass jar and extracted with 5 $\mathrm{mL}$ of acetone. The cotton ball swabs were air dried then placed in a $20-\mathrm{mL} \mathrm{VOA}$ vial and extracted with 10 $\mathrm{mL}$ of acetone.

\section{RESULTS AND DISCUSSION}

\section{Analysis of samples from ATC}

Roughly half the materials sampled during the visit to ATC were collected after the Expray kit gave a positive response. Most of the samples taken for off-site analysis were wipes made using solvent-wetted filter papers; however, some were small pieces of material or particles upon which signatures of explosives were suspected. These samples, after being extracted with acetone, were analyzed by GC/TID and GC/ECD: TNT, RDX, and HMX were the most prevalent explosives at this facility (App. B).

Assessment of coupon spiking and storage

The concentrations established for TNT, RDX, and
HMX on QA coupons (Table 1) taken from three separate batches indicate that the preparation procedure was precise (relative standard deviation less than $6 \%$ ) and that analyte recovery was quantitative $(100 \pm 11 \%$, relative to the spike concentration). The results of the two studies of storage conditions, which appear in the same table, show that this analyte concentration remained stable after 7 days when held at room temperature and after 14 days when stored in a freezer. Therefore, spiked coupons can be prepared ahead and stored for several days prior to being used to assess the performance of the HGD system. As a precaution, storage in the dark in a freezer would be preferred, as TNT is sensitive to light.

\section{Thermal treatment of spiked coupons}

Following a thermal treatment of $500 \pm 20^{\circ} \mathrm{F}(260 \pm$ $6.6^{\circ} \mathrm{C}$ ) for a period of 1 hour, extraction in acetone and analysis by GC/TID of the QA coupons showed no detectable quantity of TNT, RDX, and HMX. This means that the concentrations of TNT, RDX, and HMX were below $0.01,0.5$, and $5 \mu \mathrm{g} /$ coupon, respectively. These results support the concept that moderate thermal treatment can effectively degrade these explosive analytes. When these QA coupons are used to assess the performance of the HGD system, Method 8095 (U.S. EPA 1999) could also be used. This method of analysis has detection limits that will allow concentrations for all three explosive to be measured below 0.01 $\mu \mathrm{g}$ /coupon.

\section{Recovery of explosives using different wiping techniques}

The results of the wiping experiments in Table 2 show very different levels of analyte recovery. A cursory review of these four wiping techniques shows that the cotton swabs (balls or Q-tips) achieved greater analyte recoveries than does the filter paper. The higher recoveries seen for the Q-tips and cotton balls most likely can be attributed to the greater amount of solvent transferred to the metal surface during the wiping process. It is estimated that the small filter papers (1.5$\mathrm{cm}$ diameter) used in these experiments hold less than $0.1 \mathrm{~mL}$ of solvent, the Q-tip about $0.25 \mathrm{~mL}$, while the cotton balls holds about $2.0 \mathrm{~mL}$. Furthermore, the Qtips and cotton balls have a more fibrous texture that provides a greater surface area than does filter paper. Other general trends among these experiments were decreasing analyte recovery relative to decreasing analyte solubility in acetone (acetone solubility TNT > RDX $>$ HMX), and higher recoveries of explosives from the aluminum as compared to the rusted steel coupon surfaces.

Table 3 shows average analyte recoveries of $74 \%$ or 
Table 1. Preparation and storage of QA coupons ( $\mu \mathrm{g} /$ coupon).

\begin{tabular}{cccc} 
& TNT & RDX & $H M X$ \\
\hline Spike $^{*}$ & $1060 \pm 75$ & $863 \pm 23$ & $790 \pm 62$ \\
Coupons $(n=3)^{\star \star}$ & & & \\
Aluminum & $1070 \pm 58$ & $863 \pm 42$ & $873 \pm 25$ \\
& $(\mathbf{1 0 1 \% ) \dagger}$ & $\mathbf{( 1 0 0 \% )}$ & $\mathbf{( 1 1 1 \% )}$ \\
Rusted steel & $1080 \pm 29$ & $843 \pm 58$ & $840 \pm 44$ \\
& $(\mathbf{1 0 2} \%)$ & $\mathbf{( 9 8 \% )}$ & $\mathbf{( 1 0 6 \% )}$
\end{tabular}

Storage

A. 7 days at $22 \pm 2^{\circ} \mathrm{C}$

Aluminum

$1020 \pm 44$

(96\%)

Rusted steel

$1030 \pm 40$

(97\%)

$800 \pm 63$

(93\%)

$760 \pm 62$

$794 \pm 49$

(96\%)

(92\%)

$(86 \%)$

B. 14 days at $-12 \pm 3^{\circ} \mathrm{C}$

Aluminum

$958 \pm 36$

$(90 \%)$

Rusted steel

$978 \pm 20$

$(92 \%)$

$773 \pm 30$

$(90 \%)$

$790 \pm 64$

$(92 \%)$

$730 \pm 30$

(92\%)

$760 \pm 60$

(96\%)

*Spike, aliquots added directly to acetone.

${ }^{* *}$ Coupons from separate preparation batches.

†Percent recovery relative to spike concentration.

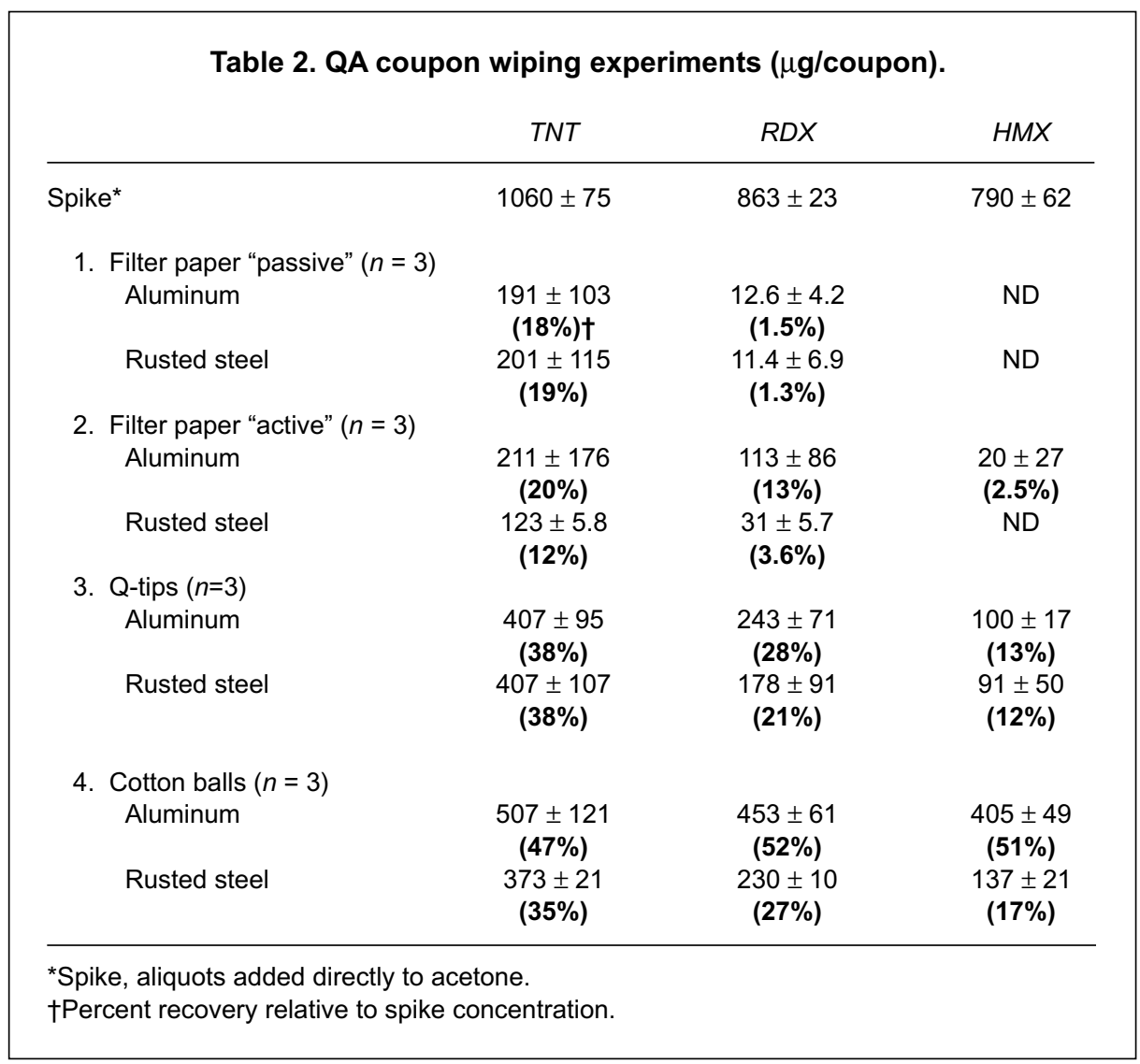


Table 3. QA coupon wiping experiment using cotton ball moistened with $\mathbf{1 . 0}$ $\mathrm{mL}$ of acetone ( $\mu \mathrm{g} /$ coupon$)$.

\begin{tabular}{lccc} 
& $T N T$ & $R D X$ & $H M X$ \\
\hline Spike* & $923 \pm 23$ & $857 \pm 15$ & $755 \pm 61$ \\
Cotton balls $(n=3)$ & & & \\
Aluminum & $760 \pm 96$ & $713 \pm 85$ & $620 \pm 96$ \\
& $\mathbf{( 8 2 \% )}$ & $\mathbf{( 8 3 \% )}$ & $\mathbf{( 8 2 \% )}$ \\
Rusted steel & $763 \pm 46$ & $677 \pm 25$ & $560 \pm 20$ \\
& $\mathbf{( 8 2 \% )}$ & $\mathbf{( 7 9 \% )}$ & $\mathbf{( 7 4 \% )}$ \\
\hline
\end{tabular}

*Spike, aliquots added directly to acetone

†Percent recovery relative to spike concentration.

better when the cotton balls were moistened with $1 \mathrm{~mL}$ of acetone. These analyte recoveries were much greater than the results obtained with the cotton balls shown in Table 2. These higher analyte recoveries for cotton balls moistened with $1 \mathrm{~mL}$ of acetone can be attributed to better control of the solvent wetting during the wiping process. When $2 \mathrm{~mL}$ of solvent was present in the cotton ball, as in the earlier experiment shown in Table 2, the excess solvent ran off the top surface of the coupon and spilled onto the table during wiping. This is a mechanism for analyte loss.
The results of wiping a hand grenade with a solvent-moistened cotton ball are shown in Table 4. The surface that was wiped was covered with small, approximately 2-mm-high cones with small crevasses between them. This initial range scrap trial showed that the cotton ball wipes recovered on average $84 \%( \pm 3.2 \%)$ of the TNT, RDX, and HMX that was present on the surface. This hand grenade contained Composition B, which is a mixture of TNT and RDX; HMX is a manufacturing impurity (about 10\%) in RDX.

Overall, cotton balls were superior to filter papers

\begin{tabular}{|c|c|c|c|}
\hline & $T N T$ & $R D X$ & $H M X$ \\
\hline \multicolumn{4}{|l|}{ Wipes } \\
\hline A & 2300 & 1500 & 240 \\
\hline B & 2800 & 1900 & 320 \\
\hline C & 620 & 340 & 54 \\
\hline \multicolumn{4}{|l|}{ Fragement ${ }^{\star}$} \\
\hline $\mathrm{A}\left(3.1 \mathrm{~cm}^{2}\right)$ & 420 & 330 & 35 \\
\hline $\mathrm{B}\left(4.1 \mathrm{~cm}^{2}\right)$ & 570 & 480 & 84 \\
\hline$C\left(3.0 \mathrm{~cm}^{2}\right)$ & 92 & 50 & $B Q^{* *}$ \\
\hline \multicolumn{4}{|l|}{ Wipe Recovery† } \\
\hline A & $85 \%$ & $82 \%$ & $87 \%$ \\
\hline B & $83 \%$ & $80 \%$ & $79 \%$ \\
\hline C & $87 \%$ & $87 \%$ & \\
\hline
\end{tabular}

Average and standard deviation of analyte wipe recovery $84 \pm 3.2 \%$.

*Amount of explosive remaining on fragment after wiping.

**Below quantitation.

†Percent of analyte present on metal fragment that was recovered in the wipe sample. 
for recovering explosives from metal surfaces. Similar observations were made by Thompson et al. (1999) when they sampled for residues of explosives from a variety of surfaces. The better performance of cotton is most likely attributable to the amount of solvent it delivers to the surface during wiping, and perhaps to the greater surface area it provides as compared to a filter paper, as mentioned earlier. Independent of wiping material, there is a general trend showing that it is easier to recover residues of explosives from a smooth surface as compared to one that is rusted (pitted). Owing to the uncertainty of recovery of analytes from rough surfaces, wiping methods in general should not be considered to be quantitative. However, there were features that make this process easy to do and eliminate unnecessary variables. On the basis of the above findings, the following procedure is currently recommended for obtaining residues of explosives from the surface of range scrap:

- Repeatedly wipe the surface with an acetone-moistened cotton ball held with metal tweezers (the cotton balls used in this study weighed $0.2 \pm 0.04 \mathrm{~g}$ and were moistened with $1 \mathrm{~mL}$ of acetone; heavier cotton balls could be moistened with greater amounts of acetone).

- Allow the cotton ball to air dry.

- Extract the cotton ball with acetone.

An additional step, filtering the extract, is necessary for analysis by Method 8330 or Method 8095. This can be done by passing a portion of the solvent extract through a $0.45-\mu \mathrm{m}$ Millex SR filter. For convenience, the cotton balls used for sample collection can be moistened before the field exercise, and stored in 20-mL VOA vials before and after a surface is wiped. The cotton balls should be air dried and extracted in a laboratory setting in preparation for analysis.

\section{SUMMARY}

This study has shown that QA coupons could be used to monitor how completely explosives decompose on range scrap treated by HGD. Coupons with spiked concentrations near $1 \mathrm{mg}$ for TNT, RDX, and HMX can be precisely prepared and were found to retain the spiked concentration when stored in a freezer for extended periods ( 2 weeks and perhaps longer). Range scrap that is known to be contaminated by residues of explosives should also be used to monitor the effectiveness of HGD. During an HGD trial, both the QA coupons and selected pieces of range scrap could be housed in a chamber that can easily be retrieved from the scrap pile.
Once retrieved, the coupons and pieces of range scrap should be submersed in acetone for extraction in preparation for analysis. The solvent extracts could be analyzed on-site using GC/TID when same-day results were needed. Rapid-turn-a-round results are likely to be needed during preliminary trials designed to establish the optimal heat soak parameters and pile configuration. Confirmation analysis by either Method 8330 or 8095 will also be done at a later date.

A two-tiered analytical process is recommended for characterizing range scrap, as the distribution and concentration of explosive residues is thought to be very heterogeneous. The first step in this process is to use on-site rapid colorimetic tests to identify the presence of explosives, so authoritative samples can be collected for subsequent analyte-specific methods of analysis. The commercially available Expray kit appears to be particularly well suited for this purpose because it is easily transported, simple to apply, and detects a wide range of explosives compounds. Once the presence of explosives has been indicated, obtaining a wipe sample or collecting a small quantity of material would follow. Although not used during the initial characterization exercise conducted for this study (laboratory trials were performed after the site visit), the wipe sample should be collected with a cotton ball moistened with acetone. This technique is easy to use and gives greater recoveries than filter paper wipes. The experimental results show that this technique is qualitative; however, it can provide a conservative estimate of the surface concentration. Solvent immersion procedures are recommended when more quantitative estimates of the concentration of explosives on range scrap are necessary.

\section{LITERATURE CITED}

ASTM (1999) Standard practice for field collection of settled dust samples using wipe sampling methods for lead determination by atomic spectrometry techniques. ASTM E 1728. American Society for Testing and Materials, West Conshohocken, Pennsylvania.

Crockett A.B., H.D. Craig, T.F. Jenkins, and W.E. Sisk (1997) Field sampling and selecting on-site analytical methods for explosives in soil. Federal Facilities Forum Issue. EPA/540/R-97/501.

Hewitt, A.D., and T.F. Jenkins (1999) On-site method for measuring nitroaromatic and nitramine explosives in soil and groundwater using GC-NPD: Feasibility study. U.S. Army Cold Regions Research and Engineering Laboratory, Special Report 99-9

Hewitt A.D., T.F. Jenkins, and T. Ranney (2000) Onsite method for nitroaromatic and nitramine explosives in soil and groundwater using a GC-thermionic ioniza- 
tion detector. 2nd International Conference on Remediation of Chlorinated and Recalcitrant Compounds, Monterey, California, 22 May 2000.

Jenkins, T.F., and M.E. Walsh (1992) Development of field screening methods for TNT, 2,4-DNT and RDX in soil. Talanta, 39: 419-428.

Jenkins, T.F., M.E. Walsh, P.G. Thorne, S. Thiboutot, G. Ampleman, T.A. Ranney, and C.L Grant (1997) Assessment of sampling error associated with collection and analysis of soil samples at a firing range contaminated with HMX. U.S. Army Cold Regions Research and Engineering Laboratory, Special Report 97-22.

Jenkins, T.F., M.E. Walsh, P.G. Thorne, P.H. Miyares, T.A. Ranney, C.L. Grant, and J. Esparza (1998) Site characterization at the Inland Firing Range Impact Area at Ft. Ord. U.S. Army Cold Regions Research and Engineering Laboratory, Special Report 989.

Parsons Engineering Science, Pacific Northwest Laboratories, Battelle Columbus Operations (1998) Design guidance manual: Low-cost disposable hot gas decontamination system for explosives contaminated equipment and facilities. Prepared for the U.S. Army Environmental Center, Aberdeen Proving Ground, Maryland, Report No. SFIM-AEC-ET-CR-98046.

Patterson, P.L. (1986) Recent advances in thermionic ionization detection for gas chromatography. Journal of Chromatographic Science, 24: 41-52.

Thompson, R.Q., D.D. Fetterolf, M.L. Liller, and R.F. Mothershead (1999) Aqueous recovery from cotton swabs of organic explosives residue followed by solid phase extraction. Journal of Forensic Science, 44(4): 795-804.

Thorne, P.G., and T.F. Jenkins (1995) Development of a field method for ammonium picrate/picric acid in soil and water. U.S. Army Cold Regions Research and Engineering Laboratory, Special Report 95-20.

Walsh, M.E., T.F. Jenkins, P.S. Schnitker, J.W. Elwell, and M.H. Stutz (1993) Evaluation of SW-846 Method 8330 for characterization of sites contaminated with residues of high explosives. U.S. Army Cold Regions Research and Engineering Laboratory, Special Report 93-5.

U.S. Environmental Protection Agency (1995) Method 8330, nitroaromatics and nitramines by high performance liquid chromatography (HPLC). In Test Methods for Evaluating Solid Waste, Physical/Chemical Methods, SW-846. Office of Solid Waste and Emergency Response, U.S. Environmental Protection Agency, Washington D.C.

U.S. Environmental Protection Agency (1999) Method 8095, Nitroaromatics and Nitramines by GCECD, Fourth Update to SW-846. (Draft IVA). 
APPENDIX A: FIRST SITE CHARACTERIZATION VISIT (1 AND 2 MAY 2000)

Light Armor Range (samples taken from collection bin)

LA-1. Metal fragment-wipe*

LA-2. Piece of aluminum warhead $(1 / 16$ in. $[0.16 \mathrm{~cm}]$ thick $)$-wipe

LA-3. Steel witness plate $(1$ in. $[2.5 \mathrm{~cm}]$ thick $)$-wipe

LA-4. RDX residue on steel plate (1/16 in. thick) —wipe

LA-5. Metal fragment-wipe

LA-6. RDX residue on steel plate (1/16 in. thick) —wipe

LA-7. RDX residue on small metal fragment-wipe

LA-8. Metal Fragment-wipe

LA-9. Metal Fragment-wipe

LA-10. Piece of aluminum warhead (1/16 in. thick) - wipe

LA-11. Steel witness plate (1 in. thick) —wipe

LA-12. Rubber gasket from Test Tiles-extraction**

LA-13. Soil/rust from bin-extraction

Dump 3 (samples taken from wooden crate)

D3-1. Orange wax from inside motor round-wipe

D3-2. WP round-wipe

D3-3. Red wax from inside round - wipe

D3-4. Inside mortar round - wipe

D3-5. 60-mm mortar-wipe

D3-6. Orange wax - extraction

D3-7. Red wax-extraction

ARL (behind Building 1134 and bins by test pad)

ARL-1. Behind 1134, witness plate (2 in. [5.1 cm] thick)-wipe

ARL-2. Behind 1134, witness plate (2 in. thick)-wipe

ARL-3. Small metal fragment-wipe

ARL-4. Aluminum propellant tube-wipe

ARL-5. Aluminum propellant tube-wipe

ARL-6. Aluminum propellant tube-wipe

ARL-7. Sand from inside aluminum propellant tube-extraction

ARL-8. Melted metal-extraction

ARL-9. Glass fiber material-extraction

ARL-10. Witness plate-wipe

ARL-11. Aluminum plate-wipe

ARL-12. Rubber gasket material — extraction

ARL-13. Soil from aluminum bin-extraction

ARL-14. Silicon gasket from aluminum bin-extraction

ARL-15. Charcoal from witness plate - extraction

ARL-16. Piece of polyethylene sheet - extraction

ARL-17. Witness plate-wipe

*Wipe - filter soaked in methanol placed on surface.

**Extraction - piece placed in acetone. 
APPENDIX B: ANALYSIS OF RANGE SCRAP SAMPLES

\begin{tabular}{|c|c|c|c|}
\hline Sample no. & $T N T$ & $R D X$ & $H M X$ \\
\hline LA-1 & - & - & - \\
\hline LA-2* & - & $\div \dagger$ & $\dagger$ \\
\hline LA-3* & - & $\dagger$ & - \\
\hline LA-4* & - & $\div \dagger$ & $\dagger$ \\
\hline LA-5 & - & - & - \\
\hline LA-6* & - & $\div \dagger$ & $\dagger$ \\
\hline LA-7* & - & $\div \dagger$ & $\dagger$ \\
\hline LA-8* & - & $\dagger$ & - \\
\hline LA-9 & - & - & - \\
\hline LA-10* & - & $\div \dagger$ & $\dagger$ \\
\hline LA-11 & - & - & - \\
\hline LA-12* & - & $\div \dagger$ & $\dagger$ \\
\hline LA-13* & $\div \dagger$ & $\div \dagger$ & $\dagger$ \\
\hline D3-1 & - & - & - \\
\hline D3-2 & - & - & - \\
\hline D3-3 & - & - & - \\
\hline D3-4 & - & - & - \\
\hline D3-5* & - & $\dagger$ & $\dagger$ \\
\hline D3-6* & $\dagger$ & $\div \dagger$ & $\dagger$ \\
\hline D3-7* & $\div \dagger$ & $\dagger$ & $\dagger$ \\
\hline ARL-1 & - & - & - \\
\hline ARL-2* & - & - & - \\
\hline ARL-3 & - & - & - \\
\hline ARL-4 & - & - & - \\
\hline ARL-5* & - & - & - \\
\hline ARL-6 & - & - & - \\
\hline ARL-7* & $\div \dagger$ & $\div \dagger$ & $\dagger$ \\
\hline ARL-8 & - & - & - \\
\hline ARL-9 & - & - & - \\
\hline ARL-10* & $\dagger$ & $\dagger$ & $\dagger$ \\
\hline ARL-11* & - & - & - \\
\hline ARL-12 & - & - & - \\
\hline ARL-13* & - & $\div \dagger$ & $\dagger$ \\
\hline ARL-14 & - & - & - \\
\hline ARL-15* & $\div \dagger$ & $\div \dagger$ & $\dagger$ \\
\hline ARL-16* & - & $\dagger$ & - \\
\hline ARL-17 & - & - & - \\
\hline
\end{tabular}

*Analyzed by Method 8095 (GC-ECD).

$\div$ Positive identification by GC-TID.

$\dagger$ Positive identification by GC-ECD (Method 8095). 


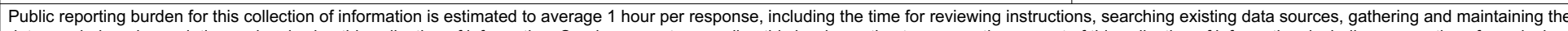

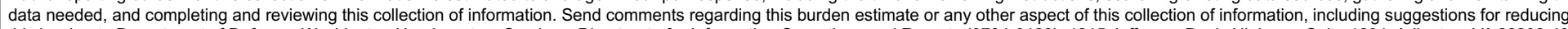

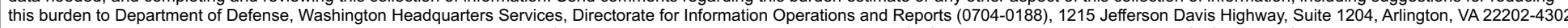

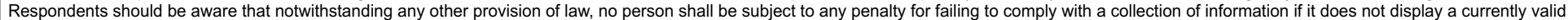
OMB control number. PLEASE DO NOT RETURN YOUR FORM TO THE ABOVE ADDRESS.
1. REPORT DATE (DD-MM-YY)
2. REPORT TYPE
March 2001
Technical Report
3. DATES COVERED (From - To)

4. TITLE AND SUBTITLE

Characterizing Range Scrap and Developing Quality Assurance

Coupons for Hot Gas Decontamination Trials

5a. CONTRACT NUMBER

5b. GRANT NUMBER

5c. PROGRAM ELEMENT NUMBER

\section{AUTHOR(S)}

Alan D. Hewitt

5d. PROJECT NUMBER

5e. TASK NUMBER

5f. WORK UNIT NUMBER

7. PERFORMING ORGANIZATION NAME(S) AND ADDRESS(ES)

8. PERFORMING ORGANIZATION REPORT NUMBER

U.S. Army Engineer Research and Development Center

Cold Regions Research and Engineering Laboratory

72 Lyme Road

Hanover, New Hampshire 03755-1290

ERDC/CRREL TR-01-7

9. SPONSORING/MONITORING AGENCY NAME(S) AND ADDRESS(ES)

10. SPONSOR / MONITOR'S ACRONYM(S)

U.S. Army Environmental Center

Aberdeen Proving Ground, MD 21010

11. SPONSOR / MONITOR'S REPORT NUMBER(S)

SFIM-AEC-ET-CR-200110

\section{DISTRIBUTION / AVAILABILITY STATEMENT}

Approved for public release; distribution is unlimited.

Available from NTIS, Springfield, Virginia 22161.

13. SUPPLEMENTARY NOTES

\section{ABSTRACT}

Characterization and decontamination of range scrap are relatively new compliance issues for military training and testing facilities. This report describes the development of an approach for characterizing energetic residues on range scrap and a method to assess the performance of a low-cost hot gas decontamination system. The procedure used to identify secondary explosives on range scrap involves a twotiered analytical process. Initially, simple wet chemical tests that can be interpreted visually were used on-site to screen readily accessible and partly enclosed surfaces, then samples were collected for analyte-specific methods of analysis. Another objective of this study was to develop quality assurance samples that could be used to optimize the hot gas decontamination treatment system and, thereafter, to satisfy regulatory agency requirements for monitoring its performance.

\begin{tabular}{|c|c|c|c|c|c|}
\hline 15. SUBJECT TERMS & \multicolumn{2}{|c|}{$\begin{array}{l}\text { Explosives } \\
\text { Field screening }\end{array}$} & $\begin{array}{l}\text { lecontamination } \\
\text { rap }\end{array}$ & \multicolumn{2}{|c|}{ Wipe sampling } \\
\hline \multicolumn{3}{|c|}{ 16. SECURITY CLASSIFICATION OF: } & 17. LIMITATION OF & 18. NUMBER & 19a. NAME OF RESPONSIBLE PERSON \\
\hline a. REPORT & b. ABSTRACT & c. THIS PAGE & & & 19b. TELEPHONE NUMBER (include area code) \\
\hline $\mathrm{U}$ & $\mathrm{U}$ & $\mathrm{U}$ & $\mathrm{U}$ & 19 & \\
\hline
\end{tabular}

